\title{
Univentricular Heart
}

Choukri Moulay Achraf $^{1 *}$, Elyazidi Salma ${ }^{2}$, Ettaoumi Youssef $^{3}$

${ }^{1}$ Cardiology department, UHC Mohamed VI, Marrakesh, Morocco

${ }^{2}$ Cardiac Surgery department, UHC Ibn Rochd, Casablanca, Morocco

${ }^{3}$ Cardiac Surgery department, UHC Ibn Rochd, Casablanca, Morocco

DOI: $10.36347 /$ sasjs.2022.v08i01.001

| Received: 29.11.2021 | Accepted: 03.01.2022 | Published: 07.01.2022

*Corresponding author: Choukri Moulay Achraf

Cardiology department, UHC Mohamed VI, Marrakesh, Morocco

Abstract

Original Research Article

Introduction: The univentricular heart refers to a pathophysiological concept in which a single functional ventricle provides both pulmonary and systemic aortic flow in parallel. The aim of this study was to conduct an epidemiological study of the univentricular heart, to study the circumstances of discovery, to analyze the problems posed by the diagnostic and therapeutic management of these patients in our Moroccan context by evaluating the diagnostic role of Doppler echocardiography and finally evaluating the evolution of these operated children. Methods: This was a retrospective study in the cardiovascular surgery department of CHU IBN ROCHD in Casablanca, over a period of 3 years from January 2017 to December 2019 involving 4 patients, whose age varies between 6 months and 7 years. Results: The sex ratio was 1 . The average age of the patients was 8 months and 6 years respectively for the pulmonary artery cerclage and for the Fontan treatment. Consanguinity, diabetes, hypertension and advanced maternal age were the main antecedents. Several circumstances of discovery have been highlighted, the most common are: perioral cyanosis in 3 patients, growth restriction with eating difficulties in 3 patients and dyspnea in 2 others. Pulmonary arterial hypertension and pulmonary stenosis were present in $50 \%$ of the patients. The diagnosis was made by echocardiography and the most common anatomical form of the single ventricle was tricuspid atresia in 2 patients. All patients were operated: 2 received pulmonary artery cerclage and 2 others received Fontan treatment, 1 of them had primary pulmonary artery cerclage in his history. In our study, no deaths were reported. Postoperative complications were dominated by atelectasis, infectious complications, bleeding and pleuro-pericardial effusion. The short and medium-term postoperative evolution was favorable for all our patients with weight gain, symptom reduction and improvement in $\mathrm{O}_{2}$ saturation.

Keywords: Fontan procedure, cavopulmonary anastomosis, univentricular heart, complex congenital heart defect.

Copyright $\left({ }^{\circ} 2022\right.$ The Author(s): This is an open-access article distributed under the terms of the Creative Commons Attribution 4.0 International License (CC BY-NC 4.0) which permits unrestricted use, distribution, and reproduction in any medium for non-commercial use provided the original author and source are credited.

\section{INTRODUCTION}

Univentricular heart disease is an uncommon group of congenital heart diseases in which a single ventricle must provide both, systemic and pulmonary output (figure1). This results in significant arterial desaturation and volumetric overload of the functionally single ventricle, responsible for more or less severe heart failure. Cardiac malformations with a univentricular circulation are numerous and diverse. In general, this pathophysiological configuration is not amenable to biventricular repair; it requires conversion to a Fontan-type circulation that allows, with univentricular function, separation of the pulmonary and systemic circuits and restoration of a "serial" circulatory system. In 1971, Fontan and Baudet published the seminal article describing a palliative correction in a patient with tricuspid atresia, in which the systemic and pulmonary circulation are placed in series, with direct anastomosis between the right atrium (RA) and the pulmonary artery, or between the right atrium (RA) and the right ventricle (RV) [1]. Since then, the indications for cavopulmonary anastomosis by direct anastomosis between the superior and inferior vena cava and the pulmonary artery have been extended to the physio-pathological correction of all functionally univentricular heart pathologies. Despite the initial success of this procedure, the longevity and effectiveness of this original circulation have been regularly questioned, leading to numerous modifications of the original operation. The usefulness of the right atrium (RA) in this connection has been questioned, giving rise to the concept of lateral tunnel or total pulmonary vena cava connection. In this operation, the superior and inferior vena cava is 
connected to the pulmonary arteries. However, while the superior vena cava undergoes a direct connection, the inferior vena cava is connected via a prosthetic conduit (figure 2). The inferior connection can be made by intra-atrial tunnel or extra-cardiac conduit.

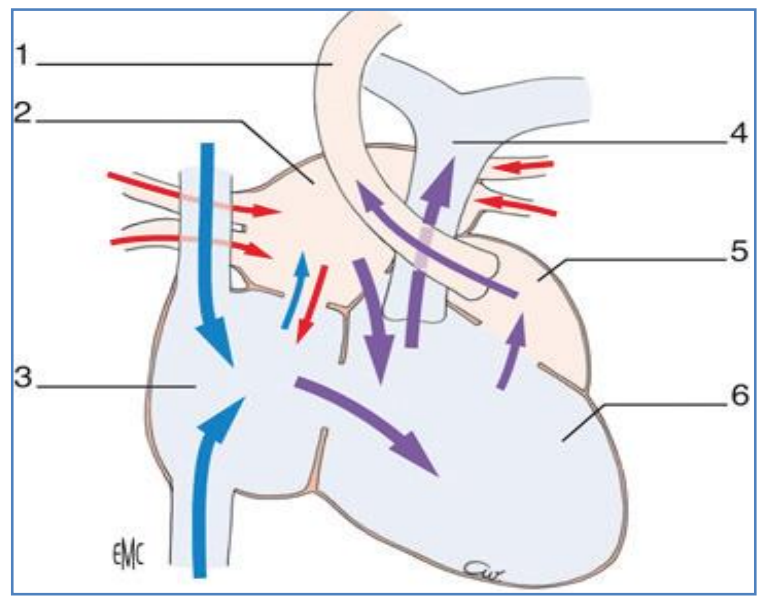

Fig-1: Pathophysiology of the heart (double inlet ventricle)

1.Aorta; 2. left atrium; 3. right atrium; 4. Pulmonary artery; 5. Accessory cavity; 6. Main ventricle



Fig-2: Total pulmonary vena cava bypass

1. Superior vena cava; 2. Pulmonary artery; 3. Inferior vena cava; 4. aorta; 5. Accessory cavity; 6. Main ventricle.

\section{MATERIAL AND METHODS}

This is a retrospective study, carried out at the cardiovascular surgery department of the CHU Ibn Rochd of Casablanca over a period of 03 years from January 2017 to December 2019. The collection of clinical and operative data of the operated patients is made from archives of medical and surgical reports. We included all children with univentricular congenital heart disease confirmed with echocardiography. We excluded all other malformative or none malformative cardiac anomalies such as cardiomyopathies, tumors, and rhythm disorders. The parameters studied are sex, age, maternal diseases, and circumstances of discovery, anatomical shape of the single ventricle, type of surgery, postoperative complications and evolution.

\section{RESULTS}

We have collected 4 cases of single ventricle. During the period concerned, 4 patients were admitted to the cardiovascular surgery department for a single ventricle. This represents $2 \%$ of all congenital heart disease hospitalized during the same period. Our patients were aged from 6 months to 7 years with an average of 40 months. The sex ratio was 1 with no gender predominance. $50 \%$ of our patients were from a consanguineous marriage. The mothers were aged from 23 to 42 years with an average of 30.5 years, 2 of them were older than 30 years. Hypertension and maternal diabetes were found in $50 \%$ of our patients. 1 of our patients aged 7 years had history of pulmonary artery cerclage at the age of 08 months and 1 other patient aged 5 years had a history of ischemic stroke at the age of 4 years. The circumstances of discovery were perioral cyanosis and delayed growth and weight in $75 \%$, dyspnea and eating difficulties in $50 \%$ and repeated respiratory infections and respiratory distress in $25 \%$ of our patients. During the clinical examination, all our patients had heart murmur, 25\% had B2 burst, $75 \%$ staturoponderal delay. All our patients had blood oxygen saturation between $75 \%$ and $90 \%$. All the patients in our study underwent a transthoracic echocardiography. This one confirmed the diagnosis, specified the type of single ventricle and the severity of these pathologies by measuring the PAPs. All patients had a good ventricular function. The most frequent anatomical form of univentricular heart is tricuspid atresia in $50 \%$ of our patients. Wide interventricular communication in $25 \%$ and double inlet single ventricle in $25 \%$ of our patients. Pulmonary arterial hypertension was present in $50 \%$ of our patients who underwent pulmonary artery banding. Preoperative cardiac catheterization was performed in $50 \%$ of our patients with tricuspid atresia who were programmed for cavopulmonary anastomosis. The mean pulmonary artery pressure in this patient was $13.37 \mathrm{mmHg}$, with extremes between 12.2 and $14.54 \mathrm{mmHg}$. Surgical treatment was indicated in all our patients. Two surgical techniques were adopted in our study: pulmonary artery cerclage and cavopulmonary anastomosis. For the cerclage, it was indicated in $50 \%$ of our patients with pulmonary arterial hypertension, including 1 cases of double inlet single ventricle and 1 cases of wide interventricular communication. For cavopulmonary anastomosis, it was indicated in 2 cases of tricuspid atresia, 01 of which had received primary pulmonary artery cerclage before bypass. Postoperative complications were observed in $75 \%$ of our patients. Pulmonary atelectasis in $50 \%$, pleuro-pericardial effusion in $25 \%$, infectious complications of the pulmonary, urinary and lining in $50 \%$ and postoperative bleeding due to clip removal in $25 \%$ of our patients. 


\section{DISCUSION}

Congenital heart disease is the most common congenital malformation. Their prevalence corresponds to $40 \%$ of all fetal malformations. Their incidence of 5 to 8 per 1000 births is generally accepted [2]. They have a variable complexity on the anatomopathological level, with relatively important physiopathological consequences. They were the subject of the first surgical attempts more than 60 years ago. Several classifications of congenital heart diseases have been proposed, the physiological classification is the most used. The physiopathology explains the clinical repercussions and the prognosis. Four main groups have been considered: left-right shunts, obstructive malformations, cyanogenic heart disease and finally heart disease that does not belong to these three main groups, called complex heart disease, which is the subject of our work [3]. Surgery for congenital heart disease is either corrective or palliative [4]. Although correction has become possible for most congenital heart diseases, palliative techniques still have an important place, when definitive repair is contraindicated at a given time or when intracardiac correction has a significantly higher mortality risk [5]. Their aim is to regulate pulmonary flow, either excessive: by cerclage or banding of the pulmonary artery trunk or insufficient: by a systemic-pulmonary shunt, or right cavopulmonary anastomosis (Glenn) or the Fontan procedure [4]

Table-1: Sex ratio of the univentricular heart (Review of the literature)

\begin{tabular}{|l|l|l|l|}
\hline & Men & Women & $\begin{array}{l}\text { Sex } \\
\text { ratio(M/W) }\end{array}$ \\
\hline Notre série & 02 & 02 & 1 \\
\hline Metras (6) & 36 & 27 & 1,33 \\
\hline M. AL Yamani (7) & 69 & 50 & 1,38 \\
\hline C. Muntaner (8) & 62 & 41 & 1,51 \\
\hline
\end{tabular}

For the sex ratio, the various studies conducted show a male predominance (table 1). However, in our study we did not find any significant difference between the two sexes. This may be due to the size of our sample.

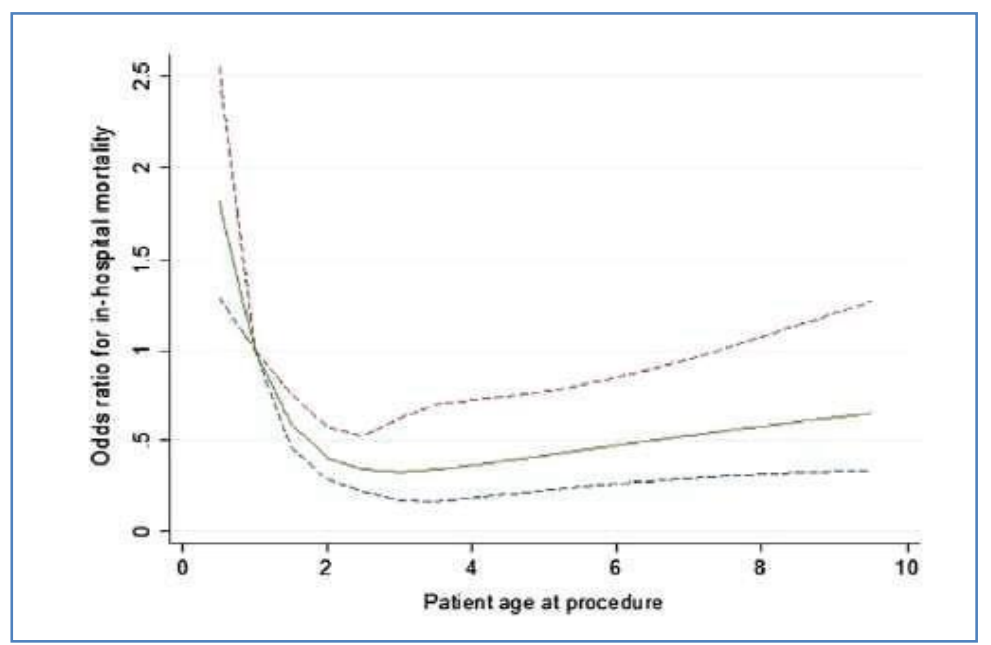

Graph-1: Association between risk of in-hospital mortality and age at Fontan surgery, from Akintoye et al. [33]. The green line represents the Odds-ratio of in-hospital mortality and the 2 dashed lines represent the $95 \%$ confidence interval.

According to the European Journal of Cardiovascular Surgery [9], the younger the age at the time of cerclage, the better the long-term results. Another American study, the results of which are shown in the following (graph 1), showed that very young age is associated with high mortality in hospital after cavopulmonary anastomosis, and this risk becomes non-negligible from the age of 7 years. According to a study conducted at the Claude Bernard Lyon 1 University [10], the most favorable results were observed in patients aged 3 to 6 years. In our study, we had a mean age of 8 months for cerclage cases and a mean age of 6 years for cavopulmonary anastomosis cases. This correlates with studies.

Table-2: Percentage of consanguinity (Literature reviews)

\begin{tabular}{|l|l|l|}
\hline AUTHORS & $\begin{array}{l}\text { NUMBERS OF CONGENITALS } \\
\text { HEARTS DISEASES }\end{array}$ & CONSANGUINITY EN \% \\
\hline Roodpeyma et al. $[11]$ & 346 & $22 \%$ \\
\hline Z. Saliba. $[12]$ & 389 & $24,4 \%$ \\
\hline M. Boussalah [13] & 213 & $25 \%$ \\
\hline S.M. Ghomari [14] & 153 & $32 \%$ \\
\hline Notre série & 04 & $50 \%$ \\
\hline
\end{tabular}


A Lebanese study by Saliba showed a higher prevalence in consanguineous marriages for all congenital heart diseases, with a higher rate of consanguinity in the single ventricle (table 2) [12]. In our series, consanguinity was found in $50 \%$ of cases. This allows us to retain the hypothesis that suggests the association between consanguinity and congenital heart disease, including single ventricle heart disease.

Table-3: Prevalence rate of congenital heart disease by maternal age

\begin{tabular}{|l|l|}
\hline $\begin{array}{l}\text { AGE MATERNEL } \\
\text { (ANS) }\end{array}$ & $\begin{array}{l}\text { TAUX DE PREVALENCE DES CARDIOPATHIES } \\
\text { CONGENITALES }\end{array}$ \\
\hline$<18$ & 37,0 \\
\hline $18-19$ & 40,0 \\
\hline $20-24$ & 34,0 \\
\hline $25-29$ & 35,0 \\
\hline $30-34$ & 47,0 \\
\hline$>35$ & 84,0 \\
\hline
\end{tabular}

Source: California Birth Defects Monitoring Program, 1995. *Per 10,000 total births

This table (table 3), taken from a study done in California, shows the prevalence rate of congenital heart disease according to maternal age, and proves that there is a relationship between the occurrence of congenital heart disease and advanced maternal age [15]. In our study, 2 women were older than 30 years that represents the most exposed age groups according to the American study.

A study in Boston showed that the prevalence of congenital heart disease is 5 times higher in newborns of diabetic mothers [16], which is similar to a recent study in Iran, which showed a 3 times higher prevalence [17]. In our study, maternal diseases were found in 2 cases, which may be in correlation with the results of the American study.

The delay of consultation in our study is explained by the ignorance of the functional signs by the parents. These signs only lead parents to consult when they become obvious. Thus, in our study, the average age of consultation is 15 months, which is clearly advanced compared to the average age of onset of symptoms, which is only 4 months.

We have two studies evaluating the relationship between congenital heart disease and its impact on nutrition and growth in children. The first study done in Ankara assessed the prevalence of malnutrition and growth retardation in 89 children with congenital heart disease [18]. The second study was an American literature review, which studied the factors contributing to statural and weight delay in children with univentricular heart disease [19]. The conclusion of those studies was that children with congenital heart disease, and especially univentricular heart disease, were more prone to nutritional disorders and growth retardation, hence the advantage of food fortification in preoperative. Growth failure in infancy may have an impact on postoperative outcomes. Thus, our results are in line with the data in the literature.

Table-4: Anatomical forms of the univentricular heart on echocardiography

\begin{tabular}{|l|l|l|l|}
\hline AUTHORS & $\begin{array}{l}\text { TRICUSPID } \\
\text { ATRESIA }\end{array}$ & $\begin{array}{l}\text { WIDE } \\
\text { INTERVENTRICULAR } \\
\text { COMMUNICATION }\end{array}$ & $\begin{array}{l}\text { DOUBLE INLET } \\
\text { SINGLE VENTRICLE }\end{array}$ \\
\hline Notre série & $\mathbf{2}$ & $\mathbf{1}$ & $\mathbf{1}$ \\
\hline A. METRAS (6) & $\mathbf{5 2}$ & - & $\mathbf{2 3}$ \\
\hline M.EL YAMANI (7) & $\mathbf{3 4}$ & - & $\mathbf{1 9}$ \\
\hline T. KALFAT (20) & $\mathbf{8}$ & - & $\mathbf{1 1}$ \\
\hline
\end{tabular}

Based on the results of other studies, tricuspid atresia is the most frequent form of single ventricle (table 4). In a study conducted by M. ELYAMANI in the cardiovascular surgery department of the Timone Hospital in Marseille, tricuspid atresia represented 69\% of the anatomical forms of single ventricle [7]. In our study, the most frequent anatomical form of univentricular heart is tricuspid atresia found in 2 patients.

For pulmonary artery banding: it is normally indicated in pulmonary hypertension, congestive heart failure caused by multiple interventricular communications, and finally complete atrioventricular canal with impossibility of septation [4, 20, 21]. Our selected indications were different from those in the literature.

Banding was indicated in 1 patient with a univentricular heart in pulmonary arterial hypertension at the age of 8 months. This patient had benefited secondarily from a cavopulmonary anastomosis. In 2 others patients, banding was indicated for 1 case of double inlet single ventricle, and 1 case of wide interventricular communication. Two surgicals approaches were adopted in our department for the 
cerclage of the pulmonary artery: the vertical median sternotomy and the ministernotomy which tend to become the two alternative approaches for their numerous advantages: first, the precision of the cerclage placement in front of the pulmonary arteries, then, the possibility of carrying out all the operative times by a single less aggressive incision [22].

There are several types of Fontan procedures since the setups have evolved over time. Isolated atriopulmonary anastomosis and intra-atrial tunnelling are complicated by rhythm disorders and thrombosis, and are therefore no longer performed. Thus, the current evolution is towards cavopulmonary anastomosis, which represents an excellent definitive palliation [23, 24 , 25]. In our study, 2 patients underwent cavopulmonary anastomosis at an average age of 6 years old, for 2 cases of tricuspid atresia, of which 1 had undergone primary banding of the pulmonary artery before bypass.

We note that the age of cavopulmonary anastomosis is high. The tendency in the literature is to perform derivation between the ages of 3 and 6 years old, with the objective of reducing the overload of the single ventricle as early as possible. Delaying cavopulmonary anastomosis is a strategy to delay the late complications.

The arterial oxygen saturation in preoperatively varied between $75 \%$ and $90 \%$, and in postoperatively between $86 \%$ and $96 \%$. During an experiment done at the University Hospital of Vaudois, the FONTAN operation allowed to raise the oxygen saturation from $82 \%$ preoperatively, to $92 \%$ postoperatively [32]. Fontan procedure had allowed improving the oxygen saturation.

The postoperative evolution was marked by a regression of the clinical signs in $100 \%$ of the patients, with a weight gain, and an improvement of the $\mathrm{O}_{2}$ saturation. The time to reoperation after palliative or reparative cerclage varies according to the teams. On average, it is 6 months around the age of 2 to 4 years $[26,27,28]$. In our study, the definitive cure was performed in 01 patient aged 7 years, after a delay of 6 years.

According to the studies, stenosis of the pulmonary artery branches by migration of the band is the most dreadful complication of cerclage [29, 30, 23]. In our series, the complications of cerclage were essentially: pneumopathy and infection of the lining. No case of obstruction was reported in our work. The early complications of the Fontan procedure are chylothorax, pleuro-pericardial effusion and ascites. Our 2 patients were complicated by pulmonary atelectasis associated with pleuro-pericardial effusion, and a postoperative bleeding due to release of the clips, which required a surgical revision.
In an epidemiological study of pulmonary artery cerclage mortality, Takayama et al. noted that low weight is a risk factor for early mortality [31]. The causes of death are mainly cardiac causes secondary to cerclage intolerance, heart failure, sepsis, pneumonia, and hemorrhagic syndrome or an extracardiac or chromosomal abnormality [26, 80, 31].

\section{CONCLUSION}

This work allows us to clarify and analyze the different epidemiological, clinical, paraclinical and therapeutic parameters in the management of univentricular heart. In the light of this study, we can recommend the following points: First, the performance of a pulmonary artery banding in case of single ventricle with pulmonary arterial hypertension $(\mathrm{PAH})$ to avoid chronic PAH contraindicating the Fontan procedure. Secondly, the importance of early management to fight the staturo-ponderal delay. Third, the realization of cavopulmonary anastomosis at a late age to delay the complications. Fourthly, the close postoperative surveillance to fight bleeding, pleuropericardial effusion and infection.

\section{REFERENCES}

1. Fontan, F., \& Baudet, E. (1971). Surgical repair of tricuspid atresia. Thorax; 26:240.

2. Walker, S.G., \& Stuth, E. (2004). Single-ventricle physiology: perioperative implications. Semin Pediatr Surg; 13:188-202.

3. Iselin, M. (1999). Classification des cardiopathies congénitales. EMC Radiodiagnostic-CœurPoumon; 32015A11:3.

4. Baudet, E. (2004). Chirurgie des cardiopathies congénitales. Archives de pédiatrie; 11; 642-4.

5. Yuan, S., \& Jing, H. (2009). Palliative procedures for congenital heart defects. Archives of Cardiovascular Disease; 102:549-57.

6. Metras, A. Résultats à moyen terme de la dérivation cavopulmonaire totale avec conduit extracardiaque réalisée au cours de la deuxième décennie de vie.

7. Al Yamani, M. Dérivation cavopulmonaire totale (extracardiaque) avec conservation d'un flux antérograde service de chirurgie thoracique et cardiovasculaire de l'hôpital de la Timone Enfants à Marseille.

8. Muntaner, C. (2020). Poor Late Outcomes after Tricuspid Valve Repair in Single Ventricle: The Experience of 103 Patients, The Annals of Thoracic Surgery.

9. D'Udekem, Y. (2011). The optimal age at Fontan procedure and the 'ticking clock' theory: do we have an answer? European Journal of Cardiothoracic Surgery; 39:140-6.

10. Karine, S. La dérivation cavopulmonaire totale chez les patients porteurs de cardiopathies univentriculaires : résultats, et pronostic selon l'âge à la chirurgie. Université Claude Bernard Lyon 1. 
11. Shieh, J. (2012). Consanguinity and the Risk of Congenital Heart Disease. American Journal of Medical Genetics Part a; 158A (5):1236-1241.

12. Saliba, Z. Consanguinité et cardiopathies congénitales au Liban. P 208.

13. Boussalah, M (2010). Épidémiologie et pronostic des cardiopathies congénitales en pédiatrie. Archives de Pédiatrie ; 17,6, S1; 150.

14. Ghomari, S (2010). Profil épidémiologique des cardiopathies congénitales à révélation néonatale à Tlemcen, Algérie. Archives de Pédiatrie ; 17,6, S1 :70.

15. Santé Canada. (2002). Les anomalies congénitales au Canada. Rapport sur la santé périnatale, 2002. Ottawa: Ministre des Travaux publics et des Services gouvernementaux Canada, 2002.

16. Rowland, T. (1973). Congenital heart disease in infants of diabetic mothers. The Journal of Pediatrics; 83(5); 815-20.

17. Naghavi. M. (2013). Risk Factors of Congenital Heart Diseases: A Case-Control Study in Northwest Iran, 5(1), 5-9.

18. Yilmaz, G. (1999). Malnutrition and growth failure in cyanotic and acyanotic congenital heart disease with and without pulmonary hypertension. Arch Dis Child, 81(1); 49-52.

19. Medoff-Cooper, B., \& Ravishankar, C. (2013). Nutrition and growth in congenital heart disease: a challenge in children. Wolters Kluwer Health | Lippincott Williams \& Wilkins.

20. Serraf, A. (2004). Traitement chirurgical de la transposition complète des gros vaisseaux. EMC Chirurgie; 1:125-60.

21. Bassil Eter, R., \& Acar, P. (2008). Canal atrioventriculaire. EMC Cardiologie; 11-940-C-40.

22. Neveux, J., \& Macé, L. (2004). Communications interventriculaires. EMC-Techniques chirurgicales-Thorax; 42-780.

23. Chauvaud, S. (2004). Atrésie tricuspide. Intervention de Fontan et dérivations cavopulmonaires. EMC Chirurgie ; 1:5-17.

24. Fontan. F (1990). Outcome after a "perfect" Fontan operation. Circulation; 81; 1520-36.
25. Hanley, F. (1999). The one and a half ventricle repair-we can do it, but should we do it? Journal of Thoracic Cardiovascular Surgery; 117:659-61.

26. Talwar, S., Choudhary, S. K., Mathur, A., Airan, B., Singh, R., Juneja, R., ... \& Saxena, A. (2008). Changing outcomes of pulmonary artery banding with the percutaneously adjustable pulmonary artery band. The Annals of thoracic surgery, 85(2), 593-598.

27. Baslaim, G. (2009). Modification of Trusler's Formula for the Pulmonary Artery Banding. Heart, Lung and Circulation; 18:353-7.

28. Cerillo, A. G., Murzi, B., Giusti, S., Crucean, A., Redaelli, S., \& Vanini, V. (2002). Pulmonary artery banding and ventricular septal defect enlargement in patients with univentricular atrioventricular connection and the aorta originating from an incomplete ventricle. European journal of cardiothoracic surgery, 22(2), 192-199.

29. Brown, S., Boshoff, D., Rega, F., Eyskens, B., Meyns, B., \& Gewillig, M. (2010). Dilatable pulmonary artery banding in infants with low birth weight or complex congenital heart disease allows avoidance or postponement of subsequent surgery. European journal of cardio-thoracic surgery, 37(2), 296-301.

30. Chantepie, A. (2005). Communications interventriculaires. EMC Cardiologie Angéiologie: 202-30.

31. Takayama, H., Sekiguchi, A., Chikada, M., Noma, M., Ishizawa, A., \& Takamoto, S. (2002). Mortality of pulmonary artery banding in the current era: recent mortality of PA banding. The Annals of thoracic surgery, 74(4), 1219-1224.

32. Ludivine, M. (2014). Complications à moyen et long terme des opérations de Fontan pour les cœurs univentriculaires. CHU VAUDOIS.

33. Akintoye, E., Veldtman, G. R., Miranda, W. R., Connolly, H. M., \& Egbe, A. C. (2019). Optimum age for performing Fontan operation in patients with univentricular heart. Congenital heart disease, 14(2), 138-139. 